\title{
MULTIPLE USE OF BENZOIN AS AN AID IN NEUROSURGICAL PRACTICE
}

\author{
THE WATERTIGHT BENZOIN DRESSING
}

RAUL MARINO JR., M.D., F.A.C.S. *

We have used commonly available alcoholic and ethereal solutions of benzoin for the last 17 years, and have found them extremely practical and easy to apply in current neurosurgical complications, as to avoid some reoperations and many types of wound infection.

Benzoin is a widely used balsamic resin obtained from various trees of the genus Styrax, and is found in commerce under the form of yellowish to brown hard brittle tears or masses, having a fragrant odor. It is very rich in a particularly impermeable resin and benzoic acid $( \pm 20 \%)$, a well known food preservative, both innocuous to health or tissues. In some countries and in the U.S.A., it is used in combination with other substances (Tincture of Benzoin Compound, U.S.P.) which helps only the adhesion of surgical tape when applied over the skin, but unfortunately does not have the properties of the more concentrated straight solutions, which we study in this paper.

\section{METHODS AND CLINICAL MATERIAL}

We have used, in the past, a $10 \%$ alcoholic benzoin tincture, currently kept in bottles of the dressing trays, or a specially made 10\%-30\% ethereal solution, which is kept in $10 \mathrm{ml}$ ampules. The solution is usually applied with gauze over the skin or scalp. The dressing gauze is simply wet with the solution and a different kind of watertight dressing is applied to the wound, according to the problem to be treated. The ethereal solutions may also be used to embed muscle, gelfoam, surgicel or oxycel gauze, which will be applied intracranially after the ether has evaporated.

We have found this substance to be highly microbicidal when applied directly over the skin, and, being impervious to water, it prevents maceration of tissue, protecting it, even when there is wound complication as infection or CS leakage. This will allow the dressing and the wound to remain dry, uninfected and safe for several days or even weeks (if properly changed).

By the same token, benzoin ethereal solution becomes very sticky when applied to muscle, gelfoam or surgicel, allowing them to adhere firmily to neighboring structures,

- Diretor, Division of Functional Neurosurgery, Hospital das Clínicas, University of Såo Paulo Medical School, Caixa Postal 8091, 01000 Såo Paulo SP, Brazil. 
thus preventing them to be carried along by CSF or blood. We have routinely used, initially a $10 \%$ alcoholic solution in the great majority of our case material during the first 10 years, in order to prevent or to treat some of the complications to be described. We have now practically abandoned the alcoholic solution, since alcohol may irritate the skin. The ethereal solution dries faster, leaving a protective film of resin over the area to be treated.

Mode of preparation - We have abandoned the commonly available dispensatory tinctures, since they routinely recommend dissolution of the raw benzoin material (Siam benzoln or Sumatra benzoin) in alcohol, followed by filtration. We have found that this procedure gives us a variable concentration of the resin, since the content of benzoin, in commercially available samples, may be only 30 to $40 \%$ after extraction. For this reason. we firstly dissolve the pulverized commercial resin in the necessary amount of ether. This is followed by filtration through filter paper. The resin is then separated from impurities and is obtained in a pure resinous form after spontaneous evaporation of the ether. This substance is used for the preparation of $10-20$ or $30 \%$ solutions, simply by re-dissolving it in ether.

\section{RESULTS}

1. Post-operative drainage (tumor bed, brain tissue ressection, etc.), ventricular drainage, ventriculography - Whenever a no 8,10 or 12 french catheter or other tubing is left in one of the above mentioned cavities for one of these purposes, after stiching the tube to the skin, the skin surface is painted with benzoin solution to facilitate adkesion of the surgical tape, and a round or square plece of haif-split gauze is wet with the solution and carefully placed around the drain.

Subsequently, pieces of dry gauze are also placed around the tubing and a watertight compressive dressing is then applied with parallel overlapping strips of regular impermeable tape (Fig. 1).

The dressing and tubing are removed after 24 or 48 hours after the craniotomy if only a post-operative wound drainage is desired. In case of ventriculography by air or positive contrast the closed stopcock-bottle or ventbag system is withdrawn after completion of the $\mathrm{X}$-ray examination or transformed into a ventricular preoperative or post-operative external drainage for as long as needed. The level of the bottle is obviously maintained under the level of the heal for siphoned drainage of post-operative cavities , and at the proper level of the head for ventricular drainage. The stopcock is kept closed in ventriculograms and is used to inject the air or other cortrast, thus avoiding repeated puncture of the ventricle. Whensoever a prolonged pre or post-operative closed system ventricular drainage is needed, the watertight benzoin dressing has to be changed every 3 to 5 days, according to the amount of leakage. Some dressing around a no 8 or smaller tubing will stay dry for one week or 10 days before they have to be changed for inspection, and we will often have the pleasing surprise to find it dry and uninfected up to the time it has to be removed. 
A
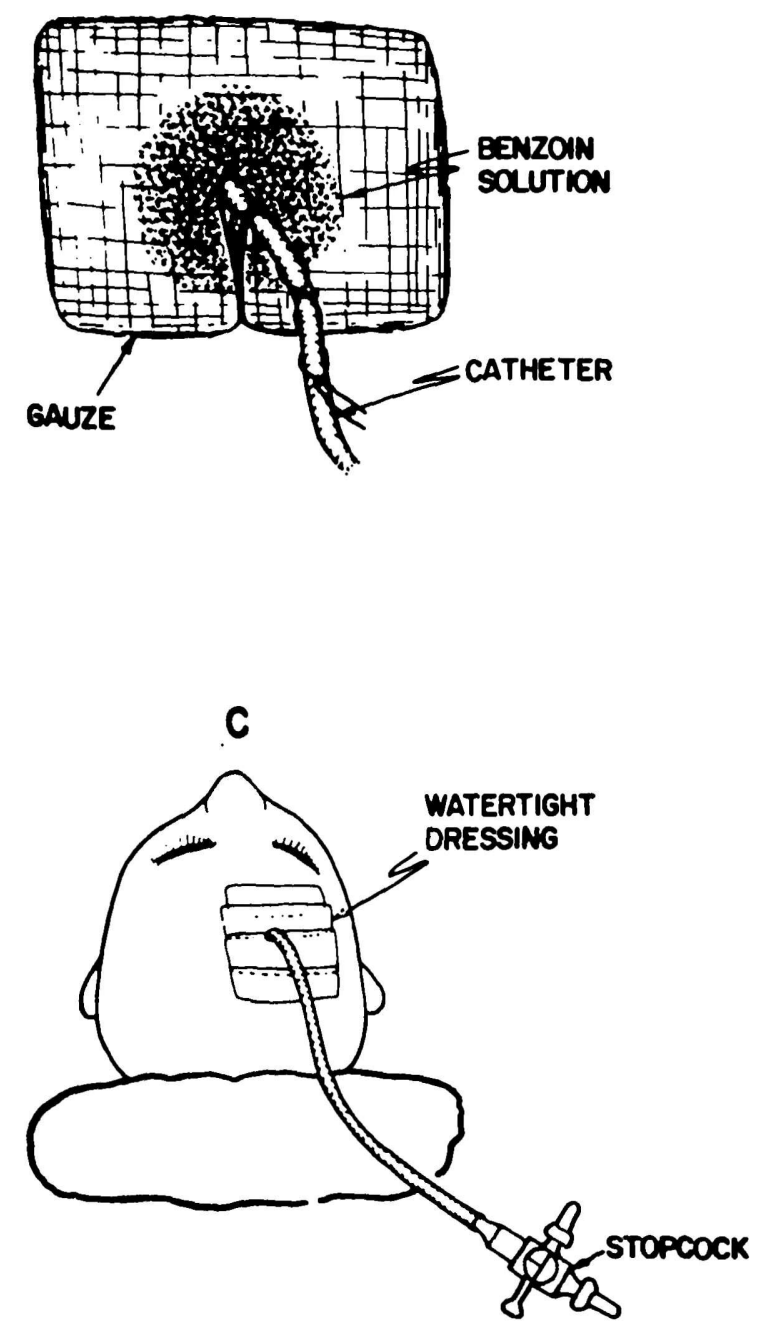

B

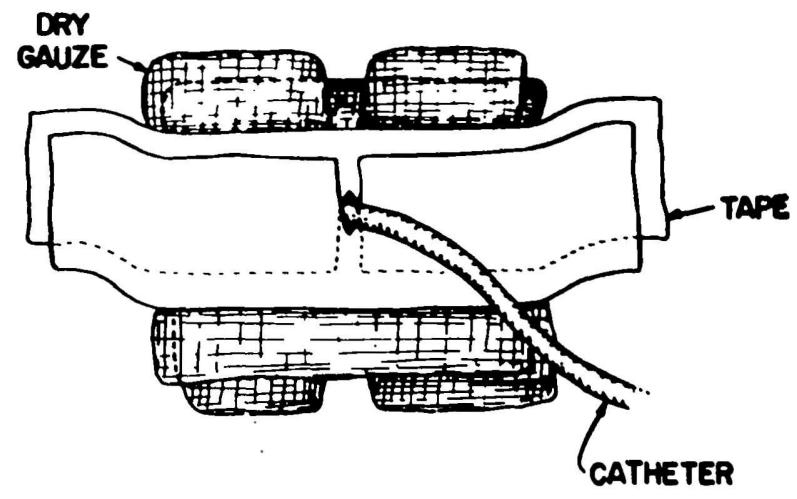

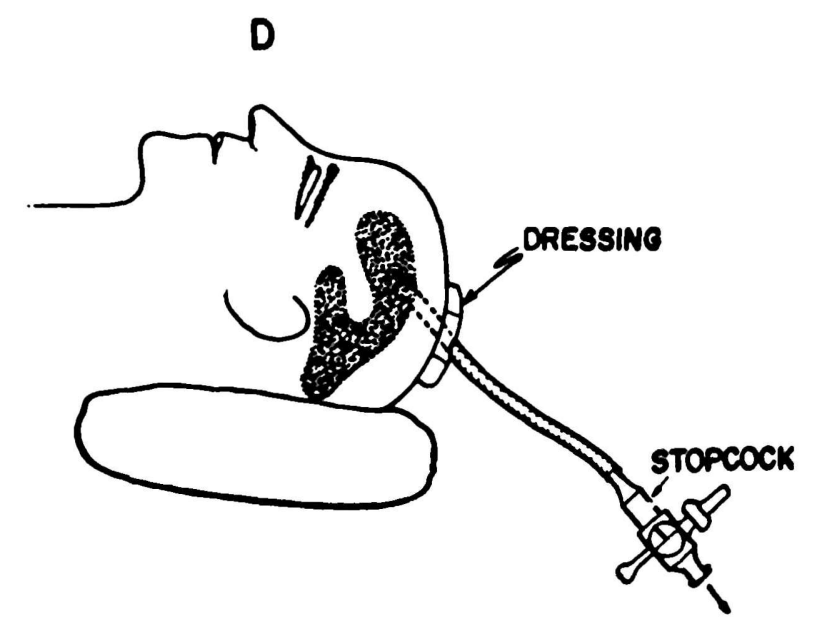

Fig. 1 - Diagrams showing the routine steps for application of the watertight benzoin dressing $(A, B, C, D)$

2. Emergency, ventricular drainage - This is the most dramatic aspect of the use of the present technique we have found through the years. The anti-microbial and waterproof properties of benzoin resin will allow a poliethylene catheter or a very thin pediatric cutdown type of tubing to stay as long as necessary in the ventricle without the common complications of scalp maceration and infection. We had cases which drained without incident for periods up to one month.

Case 1 - A seven-year old child was brought to the Neuropediatric ward (Aug. 23. 1963) with the presumptive clinical diagnosis of neuro-tuberculohis, for study and treatment. The same night the Neurosurgical resident was called and foun 1 the girl unconscious, with episodes of decerebrate rigidity and respiratory irregularities. She had known to be building up a picture of increased intracranial pressure. A modified trochar ventricular needle was quickly introduced through the coronal suture and the sharp pointed stylet exchanged for a blunt one after the bone was passed. The needle was then introduced in the lateral ventricle and $a$ thin pediatric cutdown poliethylene tube available was introduced through the needle, which was then withdrawn, leaving the tubing in place. A closed system of ventricular drainage was then installed and a watertight benzoin dressing placed around its scalp penetration. The drainage was satisfactory and the child slowly recovered until she was completely well in $3-4$ days, acting normally and able to maintain normal conversation, the increased intracranial pressure completely compensated. 
The closed system remained in place for 5 days until she was thought to be in good conditions, in order to have a ventriculogram to better explore the problem, since the arteriograms had shown an enormous ventricular dilatation. Lipiodol and air were injected through the poliethylene and, surprisingly enough, a mass was found to deviate the fourth ventricle, diagnosing a growth over the right cerebellar hemisphere (Fig. 2). Still on ventricular drainage, the child was submitted to a right sided posterior fossa craniectiomy two days latter, and after the opening of the dura a walnut-shaped mass extruded almost spontaneously, out of an adematous cerebellar tissue. It turned out to be a well encapsulated staphylococical abcess and the patient had a complete recovery. The same ventricular drainage was maintained for 48 hours after the surgery, and was pulled, after the clamping of the tubing showed no signs of recurrent intracranial pressure (Fig. 3).

Ventriculograms and/or ventricular drainage are at present carried out through twist drill holes or regular perforations. In the latter we bring out the catheter under the skin through a separate stab wound. Our previous complications are now absent after the use of the benzoin care of the skin, and no leakage or infection have occured. Moreover, even after the prolonged permanence of up to one month of these catheters in the skull, we have been able to avoid a fistula, using a compressive benzoin dressing, followed or not by a nylon or wire stich next to the stab wound, (Fig. i).

3. $C 8 F^{\prime}$ fistulas - Ocasionally we are surprised by a small area of poorly healed skin border over a cranial or spinal incision, which turns out to be a small or large site of CSF leakage. Infection readily shows up over the leaking spot, and maceration of the borders usually leads to ae corrective surgical repair or even rotation of a
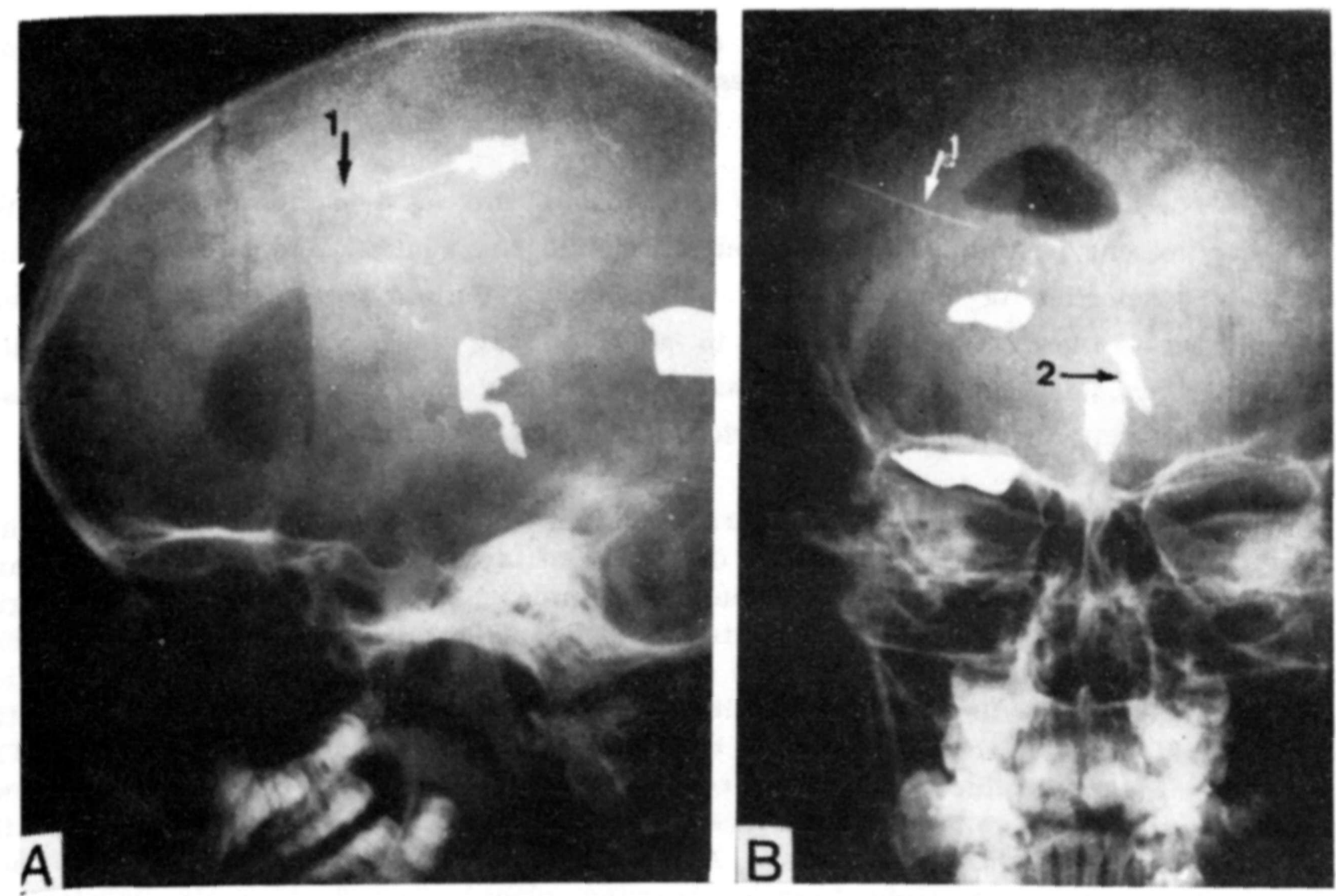

Fig. 2 - Lipiodol ventriculogram (case 1) obtained after prolomged ventricular drainage in a child with obstructive hydrocephalus and decerebrate rigidity: $1=$ thin ventricular polyethylene tubing; $2=$ deviated IVth ventricle. 

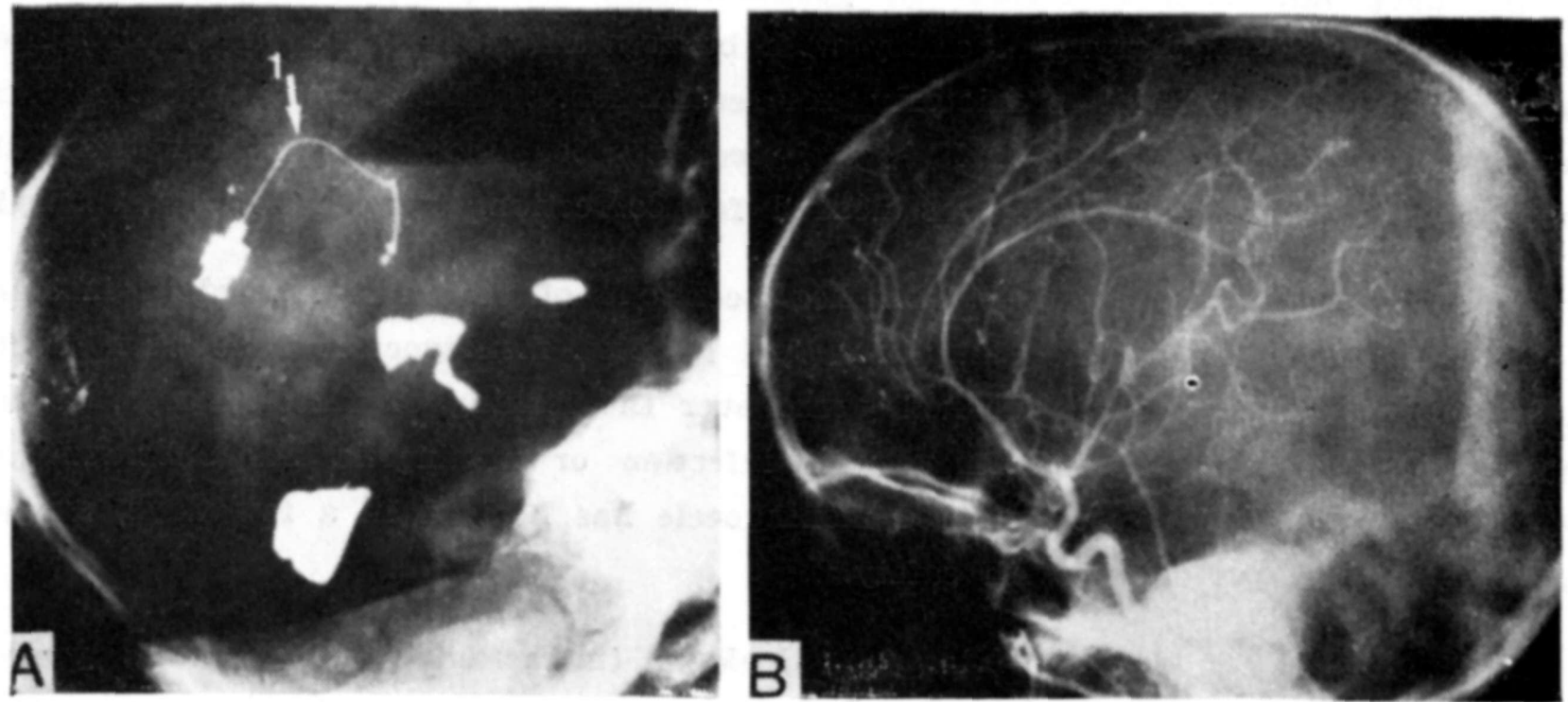

F'ig. 3 - Same as fig. 2, showing in A, a better vieno of the drainage system; $B$ shows ventricular dilatation angiographically.

flap in the worse cases. We have many times overcome this situation, applying the watertight benzoin dressing over the wound. In such cases, well padded dressings are used to avoid progressive scarification over these areas caused by decubitus or excessive pressure over the pillows or mattresses. Sterile cotton padded gauze is placed over the benzoin-wet gauze to absorb excess leakage and a watertight surgical tape closure, or head roll helmuts, should complete the dressing, thus preventing contamination from the outside. A few days are necessary for the worse leakages to show improvement until healing is completed.

Infection never progressses if benzoin embeded gauze is kept fresh, and sometimes this requires a couple of dressing changes a day. Using this procedure we have avoided many surgical corrections that would have been mandatorily carried out, even under infected circumstances. We have found this technique useful mainly in severe leakage over horseshaped or linear incision over the posterior fossa, which promptly responded, with spontaneous closure, to benzoin treatment.

The most severe case treated by this method was the following:

Case 2 - A middle-aged man was admitted (1964) for his third reoperation of a severe lumbar arachnnoiditis, this time with hyperthermia and a severe leakage of CSF through the previous skin incision. The flux was so severe that the dressing had to be changed several times a day to avoid infection. The bed sheets and mattress would be continuosly soaked with CSF and had to be frequently replaced. The fistula was completely closed after 4 days of application of benzoin watertight dressing, changed 2 to 3 times a day, and surgical correction was not programmed

Since that time we have routinely used the method for other types of CSF leakage. Thus, one case of a young girl with CSF otorrhea, after a severe episode of otitis media was promptly arrested by tamponade with ethereal-benzoin soaked gauze. Definite closure occurred 2 days after 3 changes a day of $10 \%$ ethereal solution tampons.

Up to the present time we have routinelly managed to stop leakage of posttraumatic CSF' otorrhea by this procedure, without an intervening infection. 
We have not been successful in post-traumatic or spontaneous CSF rhinorhea, tamponading the nasopharyngeal cavity with benzoin solutions. All our cases subsenquently needed a frontal craniotomy for correction. One case of post-operative rhinorhea after a tranophenoidal hypopinysectomy for metastatic cancer was also unsuccessful and re-exploration was needed for correction, using muscle and acrylic.

4. Ruptured meningoceles - This has been one of the most rewarding instances in the use of this technique. Ruptured and infected meningoceles have been treated in newborns, using a benzoin soaked gauze over the leaking or infected area, covered with a reinforced padded dressing, until infection or meningitis has subsided with proper treatment. Once the ruptured meningocele has healead in a few days, surgical corretion is then performed with safety.

5. Prevention of post-operative CSF leakage (intracranial) - For this purpose we use the $30 \%$ ethereal benzoin solution, which evaporates promptly leaving a sticky film of resin over muscle fragments, gelfoam, surgicel or oxycel gauze. This manoeuver has the advantage of giving a fairly good adhesion of these materials over the surface of the olfactory groove, coating of contaminated frontal or sphenoidal sinuses etc. and also prevents the wash off by CSF or blood. Electric cautery should never be used next to the pledgets of these materials until the ether is completely evaporated, and washing with a few drops of saline is carried out. We employ this technique routinely as a prevention and for correction of CSF leakage, after opening of frontal, sphenoidal or ethmoidal sinus.

6. Aneurysm muscle wrapping - In anterior communicating aneurysm too close to the optic nerves, where clipping or acrylic coating is not indicated, the latter for fear of chemical lesions on the surronding structures, and also in some cases of middle cerebral or other aneurysms, where muscle wrapping is the procedure of choice, we have found it quite useful to soak the lamineted hammered muscle (with or without cotton whisps) in 20 or $30 \%$ ethereal benzoin solution before the wrapping, completing the manoeuver with 2 or 3 drops of this solution over the muscle packed aneurysm to avoid wash away by blood or CSF of the muscle strips, which will firmly hold together.

7. Indwelling electrodes for depth recording - This was one of the major helps we have found benzoin solution to contribute to stereotaxic surgery. Some of these devices must remain implanted in the skull up to 1-3 months until their purpose is completed (stimulation, recording, graded lesion, telemetry etc.) and quite often will produce CSF leakage around the wires or local infection. A small ring of benzoinsoaked gauze placed around the wires will prevent those annoying complications.

8. Miscellaneous - Other uses can be contemplated sporadically for benzoin solutions. We routinely employ the above mentioned methods in several other instances as: prolonged drainage of bacterial or fungal abcesses, as protection for the skin in continuos subarachnold or epidural monitoring and recording of intracranial pressure; and as a routine spot dressing after spinal punctures after myelograms and pneumoencephalograms. In order teo prevent leakage of CSF around the ventricular catheter of an A-V- shunt for hydrocephalus, we also found it very useful to place a ring of gelfoam embeded in $10 \%$ ethereal solution fitting in the burr hole. 
A simple benzoin dressing placed around the wound of a Poppen clamp or Crutchficld clamp, used for carotid occlusion, has been routinely used and has prevented infiction over the area. The same type of dressing may be used around a tracheotomy, which will always be kept dry and uninfected.

\section{COMMENTS}

Our experience with benzoin solutions in neurosurgical practice has been quite rewarding and an evolutionary one. Based on the protective effect of benzoin tincture, commonly used in Dermatology as a local application to small fissures, cracked nipples, and indolent ulcers, we decided to check its effects in minor neurosurgical complicated wounds, and soon verified they could also be applied to major wound complications and prevention of infection, when there is a communication of the internal milieu with the contaminated evironment.

Commonly available alcoholic solutions were soon abandoned, since its alcohol content tends to irritate the skin. Our preference at present is for the 10 to $30 \%$ ethereal solutions obtained after extraction of the resin. Benzoin tincture may actually be used to prevent or to fight local infection and also as a vehicle to help adhesion of muscle or gelfoam-like materials to some anatomical structures as brain, aneurysms or dura.

\section{SUMMARY}

The author presents a survey of his experience with the use of benzoin as an aid to prevent and to treat wound complications as: CSF leakage ruptured meningoceles, prevention of leakage and wound infections, during the use of external cranial drainage, indwelling catheters or implanted cannulas and electrodes. A few other handy uses are also mentioned.

\section{RESUMO}

\section{Usos do benjoim na prática neurocirúrgica}

0 autor apresenta sua experiência pessoal com o uso da tintura de benjoim como simples, porém muito eficaz, auxílio técnico na prevenção e tratamento de certas complicações infecciosas pós-operatórias ou pós-traumáticas como: certos tipos de fístulas liquóricas, proteção da drenagem ventricular, na drenagem de craniotomias, etc. Ótimo resultado é obtido nọ fechamento de meningoceles rotas, usando-se o mesmo tipo de curativo impermeável, permitindo que estas sejam operadas com segurança ulteriormente. As propriedades adesivas dessa substância bacteriostática que repele a água, pode ser usada também na embebição de músculo ou gelfoam, no tratamento de fístulas liquóricas intracranianas ou no "colmattage" de aneurismas, além de outros usos importantes que são referidos.

Division of Functional Neurosurgery - Hospital das Clinicas - University of såo Paulo Medical School - Caixa Postal 8091 - 03000 8do Paulo, SP - Braxil. 